\title{
VALIDATING THE FIRM TECHNOLOGY ADOPTION MODEL (F-TAM)
}

\author{
Joshua Kofi Doe ${ }^{1}$, Rogier Van de Wetering ${ }^{2}$, Ben Honyenuga ${ }^{3}$ and Johan Versendaal ${ }^{2}$ \\ ${ }^{1}$ Open University, The Netherlands \\ ${ }^{2}$ Faculty of Management, Science \& Technology, Open University of the Netherlands \\ ${ }^{3}$ Ho Technical University, Ghana
}

\begin{abstract}
The revised firm technology adoption model (F-TAM), developed through the Delphi interviews and focus group discussions, was a remarkable turning point in technology adoption studies. This study aims to test the F-TAM, using data collected from Ghanaian SMEs. Data was collected from 400 SMEs in the Greater Accra Region of Ghana, using purposive sampling. Partial least squares structural equation modeling (PLS-SEM) was used for the data analysis. Data showed that, while employee factors can lead to firm adoption, firm factors of adoption do not lead to adoption if societal factors, characteristics of the innovation, and employee factors do not moderate that relationship. Societal factors do not lead to firm adoption if employee factors do not mediate it. A theoretical relevance of this study is that it challenges the idea that firm adoption of innovation will be realized, without reference to other domains of factors. This positioning of the F-TAM model is a significant departure from earlier models. For industry practitioners, these findings illustrate the essence of putting a premium on recruiting technologically savvy employees if the firm intends to adopt digital technologies.
\end{abstract}

\section{KEYWORDS}

Mobile Technologies, Firm Technology Adoption Model (F-TAM), SMEs, Adoption, Developing Countries

\section{INTRODUCTION}

Theoretical models that study individual-level technology adoption (Rogers, 2010) have been the most developed group of scholarship among the diffusion and adoption-related studies (Venkatesh et al., 2007). There have been very few models that focus on organizational/firm or societal levels (Rogers, 2010). Examples of studies that used such models include the Technology Organization and Environment (TOE) framework (Yeboah-Boateng \& Essandoh, 2014), Task Technology Fit (TTF) (Goodhue \& Thompson, 1995), the Perceived Electronic Readiness Model (PERM) (Molla \& Licker, 2005). Various researchers have tested these earlier models in different contexts such as developing counties and on different technologies. Tobin and Kuwornu (2011), for instance, studied the adoption of mobile money in Ghana at the individual level, adapting constructs from the Technology Acceptance Model (TAM) model and Diffusion of Innovation (DOI) theory. They, however, posited behavioral intention to use innovation as a mediator between the antecedents and actual adoption. One dominant idea in the many research streams that studied adoption of innovations at the individual, firm or societal level of adoption is the impression created in the models that the antecedents of behavioral intention to adopt an innovation are enough to lead to adoption; an idea that has been questioned when contextual issues are taken into consideration (Data, 2011).

Furthermore, some researchers reported that user satisfaction is a more applicable dependent variable in adoption rather than behavioral intention (Brown, Massey, Montoya-Weiss, \& Burkman, 2002; Brown, Venkatesh, Kuruzovich, \& Massey, 2008). One major implication of the contextual argument in Datta (2011) and Brown et al. (2008) is that further studies on adoption in developing countries need to develop models and instruments, with the contexts as a major consideration. This argument for context relevant models and instruments is on the premise that the need to ground research in context is as strong as the need to ground research in the international scientific discourse (Röling, Hounkonnou, Offei, Tossou, \& Van Huis, 2004). It is also premised on the idea that adopters' choices regarding adoption are based on rationality embedded in 
culture and the context of adoption rather than persuasion (Agarwal, 1983; Dewan \& Kraemer, 2000; Shih, Venkatesh, Chen, \& Kruse, 2013; Amoako, Doe, \& Deheer, 2014).

The quest for context relevant factors that lead to the adoption of innovation in developing countries has therefore been on-going since Data (2011). In Ghana, this drive increased, owing to the recent discussion of factors that explain the rapid growth of mobile technologies (Attopley, 2016; Tagoe, 2016; Bank of Ghana, 2016). Doe et al. (2018) refined the F-TAM model (Doe et al., 2017), which sought to explain the adoption of mobile innovations at the SME level relying on qualitative data (focus group interviews). This contribution was a significant departure from the earlier norm of adapting constructs (Data, 2011; Brown et al., 2008). This new path of measuring firm level adoption while accounting for the influence of other levels of adoption, and with the model developed from the socio-cultural context of adoption, set forth a new stream of adoption studies. Paramount among such new streams of studies include the development of measuring instruments, quantitatively testing of the instrument in similar contexts, and final validation of the model with data across countries. This study, therefore, aims to quantitatively test one of such current context relevant models, the revised firm technology adoption model (F-TAM), using data collected from Ghanaian SMEs.

\section{THEORETICAL BACKGROUND}

\subsection{Previous Literature on Adoption of Innovations}

Various theories of models used in studying innovations at the personal, organizational, and societal levels include Theory of Reasoned Action (TRA) (Fishbein \& Ajzen, 1975), Theory of Planned Behaviour (TPB) (Ajzen, 1985), Decomposed Theory of Planned Behavior (DTPB) (Taylor \& Todd, 1995), Integrated Model of Technology Acceptance (IMTA) (Venkatesh, Speier \& Morris, 2002), TAM (Venkatesh \& Bala, 2008), UTAUT 1 \& 2 (Venkatesh, Thong \& Xu, 2012), and Dynamic Use Diffusion Model (DUDM) (Shih, Venkatesh, Chen, \& Kruse, 2013), for the study of individual adoption of technology. Models developed for the study of societal level adoption include Culture, Policy \& Technology Framework (CPT) (Bajaj \& Leonard, 2004). At the firm level, models such as Technology, Organization and Environment Framework (TOE) (Tornatzky, Fleischer \& Chakrabarti, 1990), Task-Technology Fit (TTF) (Goodhue \& Thompson, 1995), and Perceived Electronic Readiness Model (PERM) (Molla \& Licker, 2005). Varying results, however, were reported when these models were applied to developing country contexts (Datta, 2011). The varying results highlight the need for a model that is developed with data from a developing county context.

In the recent scholarly discussion of digital technologies such as data mining, cloud computing, social media, cybersecurity, and mobile applications, a strong emphasis has been on adoption studies (Doe et al., 2018; Masocha \& Dzomonda, 2018; Asongu, 2018; Adjei \& Odei-Appiah, 2018). Examples of such studies in Ghana includes Adadevoh (2018), Adjei and Odei-Appiah (2018) and Ansong and Boateng (2018). Similar studies in other developing countries include Chaouali, Souiden, and Ladhari (2017), Asongu (2018) and Masocha and Dzomonda (2018). It is worth noting, however, that apart from Doe et al. (2018), none of these studies was done with a model initially developed from developing country contexts. Following the groundbreaking study of Doe et al. (2018), an F-TAM measuring instrument (Doe et al., nd) was subsequently developed to aid researchers to measure or study firm technology adoption among SMEs.

\subsection{F-TAM}

The revised F-TAM (Doe et al., 2018) was a contextual validation of the initial F-TAM (Doe et al., 2017) through two rounds of Delphi panel interviews of both academics and industry experts. To understand the model refinement process, a highlight of the Delphi process in that study is worth mentioning here. In the first round of interviews, ten industry expert were purposively sampled (Saunders et al., 2007; Yin 1994) from an industry awards list, showing the firms that introduced the most adopted mobile digital innovations. The participants were completely anonymous. Five academic participants were sampled using a snowballing technique of academics who had a Ph.D. and were published in the area of study. Academic membership was therefore not entirely anonymous. The respondents commented on the original variables and relationships of the F-TAM model (Doe et al., 2017). New variables and relationships discovered were added as part of the second round of interviews. In the second round, respondents commented on the revised variables, restricting 
the comment to an agreement, disagreement, and neutrality. Researchers role in the process was restricted to that of a planner, facilitator, recorder and reviewer or synthesizer of the data (Avella, 2016).

Delphi interviews were administered orally and recorded, or sent by email. Voice data was transcribed into text, using, content analysis and pattern matching (Yin, 2013, Ezzy, 2002),) to scan out the main issues being discussed and to confirm, add to or subtract from the original model. Cross-case analysis was conducted using the concept-centric approach (Webster \& Watson, 2002) to assemble the discussion into building blocks or themes that refine the existing model with pattern matching (Yin, 2013). A variable index was developed in that study and used to determine the weight of consensus for each variable or relationship agreed upon by the end of the second round (Doe et al. 2018).

These validation processes captured new constructs and propositions that refined the original F-TAM. The relevance of the original F-TAM, as well as the revised F-TAM, is that it posits antecedents of firm-level adoption while accounting for the influence on the individual (employee) adoption and societal adoption. Thus the revised F-TAM proposes that employee level variables of Perceived Ease of Use, Perceived Usefulness, Perceived Indispensability, Perceived Social Influences, Trial Feedback, and Employee Self Enhancement Motives will taken collectively, lead to firm adoption, and influence firm factors. Following the model's logic, Doe et al. (2018) proposed the following hypotheses:

\section{H1: Personal level factors lead to firm adoption;}

H2: Personal level factors influence firm factors.

At the firm level, organizational factors such as Technological Readiness Managerial Innovativeness, Organizational Readiness, Strategic Fit with Operations, Ease of Support, and Organizational Culture, in addition to industry factors such as Customer Needs/demand, Competitive Pressure, and Partner Requirement will combine at the firm level to influence firm adoption. Doe et al. (2018) hypothesized this as follows:

\section{H3: Firm factors lead to firm adoption.}

Societal level factors proposed in the revised F-TAM (Doe et al., 2018) are Government Policy, Government Championship, Government Laws, Innovation Infrastructure, Opinion Leadership and Successive Government Commitment to promoting the diffusion of the innovation will, taken together, lead to firm adoption, influence employee factors, influence firm factors and moderate the relationship between firm factors and firm adoption. These particular relationships are hypothesized as follows:

H4: Societal level factors influence personal level factors;

H5: Societal level factors influence firm-level factors;

H6: Societal level factors lead to firm adoption.

Rogers (1962) theorized how the characteristics of innovation affect its adoption. Later theories and models that focused on technology adoption did not anticipate this construct of technology characteristics. The revised F-TAM, however, has placed great emphasis on the technology characteristics as a strong influence on individuals, firms, and society at large. These technology characteristics are Observability, Flexibility, Complexity and Relative Advantage. They are hypothesized in this study as follows:

H7: Technology factors influence employee factors;

H8: Technology factors influence firm-level factors;

H9: Technology factors influence societal factors.

\section{METHODOLOGY}

Data for the study was collected from 400 SMEs, purposively sampled (Straits \& Singleton, 2017) from the Greater Accra Region of Ghana. Trained data collectors were engaged to collect data. The data collection instrument was designed and validated an evaluation process of self-review, expert review of four experts, and focus group discussion involving twelve academics (Leeux et al., 2008). Question items in the instrument were either adapted from relevant previous studies related to the purpose of this study or crafted and taken through the evaluation process. During the evaluation process, the authors checked for length (Holbrook et al., 2006; Fink, 2003) grammar (Donyei, 2003; Leeux et al., 2008); simplicity (Bhandari \& Wagner, 2006); 
social desirability (Brace, 2004); double-barreled questions (Leeux et al., 2008); and question order (Baker, 2003). The instrument was also taken through a field test (Leeux et al., 2008), with a sample size of 25 respondents (Fowler, 1995, Converse \& Presser, 1986, Sheatsley, 1983, Sudman, 1983, Converse \& Presser, 1986). The instrument was found to be valid and reliable (see Doe et al. nd) in testing SME for the F-TAM model of technology adoption at the firm level. Steiger (1988) emphasizes that the exact statistical tools used in the quantitative analysis must be reported to support a reliable replication of a study. Partial least squares structural equation modeling (PLS-SEM) was used (SmartPLS Release: 3.2.7) (Ringle et al., 2015) for the data analysis. Except for firm adoption, constructs are measured reflectively, because the individual items were similar and correlated well such that the deletion of some items will not significantly affect the definition of the construct. Model indicators are suggested by the underlying construct and have positive and desirably high intercorrelations (Coltman, Devinney, Midgley, \& Veniak, 2008).

\section{DATA ANALYSIS}

\subsection{Assessment of The Measurement Model}

Confirmatory factor analysis tests of convergence and discriminant validity for the reflective constructs (Lings \& Greenly, 2010; Hair et al., 2016) are relevant for structural equation models. The minimum Cronbach's alpha recommended for adequate convergent validity is 0.6 for exploratory studies (Hair et al., 2016; Chin, 2010). The recommended minimum composite reliability and average variance extracted (AVE) estimates are 0.7 and 0.5 respectively (Hair et al., 2016). Guided by these recommendations, we show the convergent validity test for the measurement model in table 1 . An examination of the initial loadings showed that Personal Factors was measured using six constructs, with three items under various constructs loading below the minimum threshold. Firm Internal Factors was measured using six constructs with two items under different constructs loading below the minimum threshold. Firm External Factors was measured using three constructs, with two items under organization partner requirement, two items under needs of customers, and one item under competitive pressure all had loadings below the minimum threshold. We measured Societal Factors with six constructs, with two items under government championship, and four other items under various constructs all had loadings below the minimum threshold (Hair et al., 2016). Technological Characteristics was measured using four constructs, with four items under various constructs loading below the minimum threshold. All items with loadings below the minimum threshold (all had loadings below the minimum threshold of 0.6 (Hair et al., 2016) were deleted and the model re-run to obtain acceptable loadings. Therefore, following recommendations by Hair et al. (2016) and Chin (2010) convergence validity has been met for the six constructs under personal factors, six constructs under firm internal factors, three constructs under firm external factors, six constructs under societal factors, and four constructs under technological characteristics.

\subsection{Discriminant Validity Assessments}

Discriminant validity is about the uniqueness of a construct. Hair et al. (2016) and Hensler et al. (2015) recommend assessing the Fornell-Lacker criterion, item cross-loadings, and the heterotrait-monotrait ratio (HTMT) criterion to test discriminant validity. Henseler et al. (2015) argued that cross-loadings of indicators explain zero percent of discriminant validity while Fornell-Larcker and HTMT criterions explained 20.82 percent and 97 to 99 percent of discriminant validity respectively. This study therefore examines the discriminant validity of the reflective constructs using Fornell-Larcker and HTMT criteria.

Discriminant Validity- Fornell-Larcker Criterion- The square root of the average variance extracted estimates for each of the 25 reflective constructs is higher than the inter-construct correlations between them (Fornell \& Lacker, 1981; Hair et al., 2016). Thus each construct is distinct and differs from the other measurement constructs in the model hence discriminant validity is met, as shown in table 1. 
Table 1. Convergence \& Discriminant Validity of Reflective Constructs

(Square root of AVEs in diagonal bold)-Fornel \& Lacker Criterion

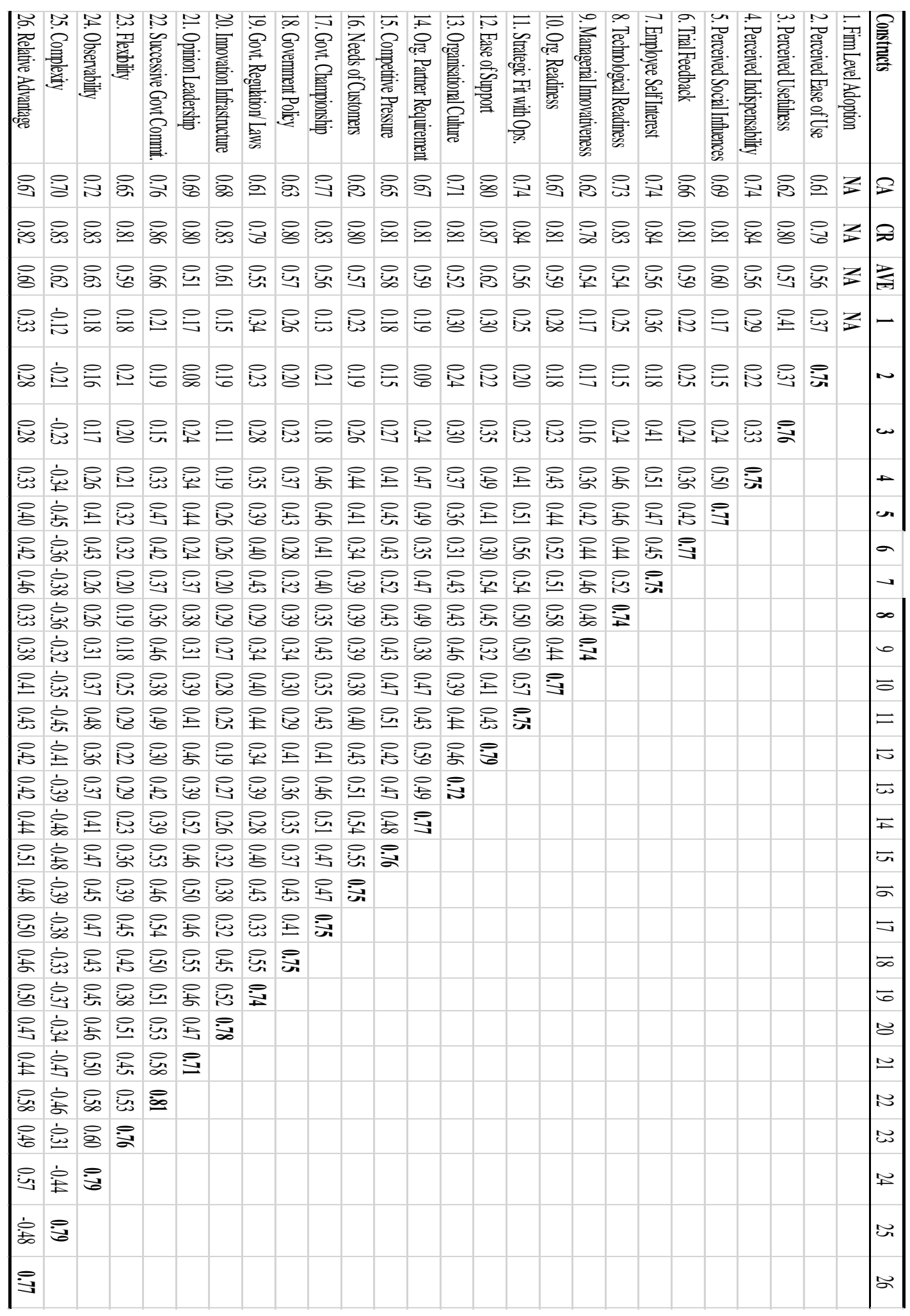

All correlations are positive and mostly significant. Source: Field Data (2018) 
Discriminant Validity- Heterotrait-Monotrait Ratio- Although Henseler et al. (2015) provided three HTMT criteria: HTMT specificity ratio of 0.90 , HTMT specificity ratio of 0.85 and HTMT inference score ranging from -1 to $1(-1<$ HTMT < 1$)$ as an indication of distinctiveness, they argued that HTMT.85 is the most conservative criterion. HTMT inference is the most liberal whilst HTMT0.9 lies in between the two extreme categories in terms of specificity rates. The authors, therefore, adopt the $0.9\left(\mathrm{HTMT}_{0.9}\right)$ as a criterion for assessing discriminant validity (Gold et al., 2001; Teo et al., 2008; Henseler et al., 2015). The HTMT result presented in this study shows that none of the correlations exceeded 0.9 thus confirming discriminant validity for the 25 reflective constructs in the model.

\subsection{Structural Model}

The structural model examines the construct relationships within the context of the conceptual framework or hypotheses/propositions to be tested. This study examines the relationships between the higher-order constructs (independent variables) and firm-level adoption. Since the structural model involved higher-order constructs, the following procedures were applied based on recommendations by Hair et al. (2016) and Becker, Klein, and Wetzels (2012).

Personal factors were measured using six constructs. Personal factors were modeled as a reflective-formative type II construct (Becker, Klein, \& Wetzels, 2012) with the six first-order reflective indicators. Firm internal factors were measured using six first-order constructs. Firm external factors were measured using three first-order constructs. General firm-level factors were modeled as a reflective-formative type II construct (Becker et al., 2012) with nine first-order reflective indicators. Societal factors were measured using six constructs. Societal factors, thus, were modeled as a reflective-formative type II construct (Becker et al., 2012) with six first-order reflective indicators. Technological characteristics were measured using four constructs. Technological characteristics were modeled as a reflective-formative type II construct (Becker et al., 2012) with six first-order reflective indicators. A correlation matrix of the five high-order constructs (table 2.) shows significant (strong) positive correlations between firm adoption, personal factors, firm-level factors, societal level factors and technology characteristics ( $p<0.01$ in all cases). Even though some of the indices are closer to 0.8, several authors argue that correlation values alone are not conclusive to establish multicollinearity. The Variance Inflation Factors, tolerance, collinearity, and conditional indices are additional analysis that are relevant and were done (Hair et al., 2014, Hair et al., 2016). The results show that all the variance inflation factors (VIFs) are lower than 5 , which is recommended to prove the absence of collinearity problems (Hair et. al. 2014). Therefore, the five high-order construct model does not present a collinearity problem.

Table 2. Correlation Matrix for Second/high-order Constructs

\begin{tabular}{l|llllc}
\hline High level Constructs & $\mathbf{1}$ & $\mathbf{2}$ & $\mathbf{3}$ & $\mathbf{4}$ & $\mathbf{5}$ \\
Firm-level Adoption & 1 & & & & \\
Personal Level Factors & $0.368^{* * *}$ & 1 & & & \\
Firm Level Factors & $0.278^{* * *}$ & $0.776^{* * *}$ & 1 & & \\
Societal Level Factors & $0.246^{* * *}$ & $0.617^{* * *}$ & $0.733^{* * *}$ & 1 & \\
Technology characteristics & $0.276^{* * *}$ & $0.334^{* * *}$ & $0.416^{* * *}$ & $0.592^{* * *}$ & 1 \\
Note: $* * *$ Correlation is significant at $\mathbf{0 . 0 1}$ level of significant & & & $\mid$
\end{tabular}

Table 3 provides a summary of the hypotheses test and conclusions made in this study. Of the nine study hypothesis, five are supported by the data. 
Table 3. Summary of Hypotheses Assessment

\begin{tabular}{llccc}
\hline $\begin{array}{l}\text { Proposi } \\
\text { tions }\end{array}$ & Definition & $\begin{array}{c}\text { Standard } \\
\text { Beta }\end{array}$ & $\begin{array}{c}\text { Bootstrap } \\
\text { t-value }\end{array}$ & $\begin{array}{c}\text { Hypothesis } \\
\text { results }\end{array}$ \\
\hline P1 & Personal level factors lead to firm adoption & $0.480^{* * *}$ & 4.900 & $\begin{array}{c}\text { Supported } \\
\text { P2 }\end{array}$ \\
P3 & Fersonal level factors influence firm factors & $0.524^{* * *}$ & 12.190 & Supported \\
P4 & Societal level factors influence personal level factors & -0.029 & 0.229 & Not Supported \\
P5 & Societal level factors influence firm level factors & $0.646^{* * *}$ & 14.265 & Supported \\
P6 & Societal level factors lead to firm adoption & $0.410^{* * *}$ & 7.633 & Supported \\
P7 & Technology characteristics influence employee factors & -0.131 & 1.141 & Not Supported \\
P8 & Technology characteristics influence firm-level factors & -0.049 & 0.950 & Not Supported \\
P9 & Technology characteristics influence societal factors & $0.592^{* * *}$ & 0.029 & Not Supported \\
\hline
\end{tabular}

Note: $* * *$ Significant at $\mathrm{p}<0.01 ; * *$ Significant at $\mathrm{p}<0.05 ; *$ Significant at $\mathrm{p}<0.10$

The hypotheses test results are explained as follows:

H 1: Personal level factors lead to firm adoption. A positive and significant association exists between personal level factors and firm adoption of mobile money innovations $(\beta=0.480, t=4.900, p<0.01)$. Therefore, hypothesis $1(H I)$ is supported in the present context. These outcomes suggest that the attitudes and perceptions of employees in a firm (SME) towards mobile money innovation, drive adoption of mobile money innovations, confirming a proposition of Doe et al. (2018).

H2: Personal level factors lead to firm factors. A positive and significant association exists between personal level factors and firm-level factors $(\beta=0.524, \mathrm{t}=12.19, \mathrm{p}<0.01)$. Therefore, hypothesis $2(H 2)$ is supported in the present context. This means employees attitudes and perceptions in a firm (SME) drive firm-level factors, confirming another proposition of Doe et al. (2018).

H3: Firm factors lead to firm adoption. The relationship between firm-level factors and firm adoption of mobile payment innovations was not statistically significant $(\beta=-0.029, \mathrm{t}=0.229, \mathrm{p}>0.05)$. Therefore, hypothesis $3(H 3)$ is not supported in the present context. This outcome means that firm-level factors do not necessarily drive adoption. This contradicts a proposition of Doe et al. (2018) that suggested that firm factors will lead to firm adoption. A significant indication of the findings in hypothesis $\mathrm{H} 1, \mathrm{H} 2$, and $\mathrm{H} 3$ is that they challenge earlier models such as PERM model and TTF that suggest that firm factors lead to firm adoption. Perhaps, if those studies had decoupled employee factors from other firm-level factors, the results of those studies would have been different.

H4: Societal level factors influence personal level factors. A positive and significant association exists between societal level factors and personal level factors $(\beta=0.646, t=14.265, \mathrm{p}<0.01)$. Therefore, hypothesis 4 (H4) is supported in the present context. This means societal level factors drive personal level factors, confirming another proposition Doe et al. (2018).

H5: Societal level factors influence firm-level factors. A positive and significant association exists between societal level factors and firm-level factors $(\beta=0.410, t=7.633, p<0.01)$. Therefore, hypothesis 5 (H5) is supported in the present context. This outcome suggests that societal level factors drive firm-level factors, confirming Doe et al. (2018) propositions.

$\boldsymbol{H}$ 6: Societal level factors lead to firm adoption. The relationship between societal level factors and firm adoption of mobile payment innovations was not statistically significant $(\beta=-0.131, \mathrm{t}=1.141, \mathrm{p}>0.05)$. Therefore, hypothesis 6 (H6) is not supported in the present context. This means societal level factors do not necessarily drive adoption. Juxtaposing this finding with $H 1$, the evidence demonstrates that societal level factors rather drive personal level factors which subsequently drive adoption. This finding also contradicts a proposition of Doe et al. (2018) that societal factors will drive firm adoption. It also contradicts propositions in other models such as the Culture, Policy and Technology framework (Bajaj \& Leonard, 2004)

H7: Technology factors influence employee factors. The relationship between technological factors and personal/employee factors was not statistically significant $(\beta=-0.049, \mathrm{t}=0.950, \mathrm{p}>0.05)$. Therefore, proposition $7(\boldsymbol{P} 7)$ is not supported in the present context. This means technological factors do not necessarily influence personal/employee factors as contrarily suggested by Doe et al. (2018). 
$\boldsymbol{H}$ 8: Technology factors influence firm-level factors. The relationship between technological factors and firm level factors was not statistically significant $(\beta=-0.001, \mathrm{t}=0.029, \mathrm{p}>0.05)$. Therefore, proposition $9(\boldsymbol{H} 8)$ is not supported in the present context. Again, this means technological factors do not necessarily drive firm-level factors, as contrarily suggested by Doe et al. (2018)

$\boldsymbol{H}$ 9: Technology factors influence societal factors. A positive and significant association exists between technological factors and societal level factors $(\beta=0.592, t=14.660, p<0.01)$. Therefore, proposition $9(\boldsymbol{H 9})$ is supported in the present context. This means technological factors drive societal level factors, confirming another proposition in Doe et al. (2018).

\subsection{Additional Study Observations}

The structural model presented in figure 1 suggests a direct effect of technology characteristics on firm adoption as well as possible mediational effects of personal and societal factors. Likewise, we discovered that technological characteristics moderate the relationship between firm-level factors and firm adoption.

This study discovered that a positive and significant association exists between technological characteristics and firm adoption $(\beta=0.165, \mathrm{t}=1.984, \mathrm{p}<0.05)$. This means technological characteristics drive firm adoption, confirming Rogers' (1962) diffusion theory as still being relevant in the adoption of any innovation. This study also discovered that technological factors moderate the relationship between firm-level factors and firm adoption $(\beta=0.12, t=2.242, p<0.05)$. Thus even though firm factors did not lead to firm adoption, technological factors strengthen the relationship between firm-level factors and firm adoption.

Next to the observation, we discovered some remarkable mediation effects. First, we discovered that personal factors fully mediate the relationship between societal factors and firm adoption. Therefore, contrary to hypothesis 6 (H6) societal factors instead have an indirect effect on firm adoption.

We also found that societal level factors fully mediate the relationship between technological characteristics and firm-level factors. Therefore, contrary to hypothesis 8 (H8) of this study, technological characteristics rather have a significant indirect effect on firm-level factors through societal level factors.

Finally, we found that Societal level factors fully mediate the relationship between technological factors and personal factors. This implies that technological characteristics have a significant indirect effect on personal factors through societal level factors. Therefore, contrary to hypothesis 7 (H7) of this study, which proposes a direct effect of technological characteristics on personal factors, the effect is an indirect one.

\section{SUMMARY, CONCLUSION, AND DISCUSSION}

This paper sought to test the F-TAM, with associated hypotheses, using data collected from Ghanaian SMEs. The hypotheses were tested using PLS-SEM. The study found a positive and significant relationship between personal factors and adoption, personal factors and firm-level factors, societal level factors and personal factors, societal level factors and firm-level factors, technological factors and societal level factors, and technological factors and firm adoption.

Furthermore, societal level factors, personal factors, and technological factors were all found to moderate the association between firm-level factors and firm adoption. As a result, five of the nine hypotheses of the study are supported in the present context. The study also found a mediating effect of personal level factors on the relationship between societal level factors and adoption, a mediation effect of societal factors on the relationship between technology factors and firm-level factors, and also between technology factors and personal factors. It is important to note that, if this study had examined the effect of firm-level factors alone on adoption, we would have found a significant relationship as earlier studies had found. However, disaggregating personal level factors exposes the flaw in that idea.

Our findings confirm most of the hypothesis in the revised F-TAM version (Doe et al., 2018), at the same time challenging some propositions in other models such as the CPT framework, PERM, TOE models. Striking revelations from this study that calls for further studies include the following:

While employee factors can lead to firm adoption, firm factors of adoption, mainly posited by models such as the PERM model and TTF do not lead to adoption if societal factors, characteristics of the innovation, and employee factors do not moderate that relationship. 


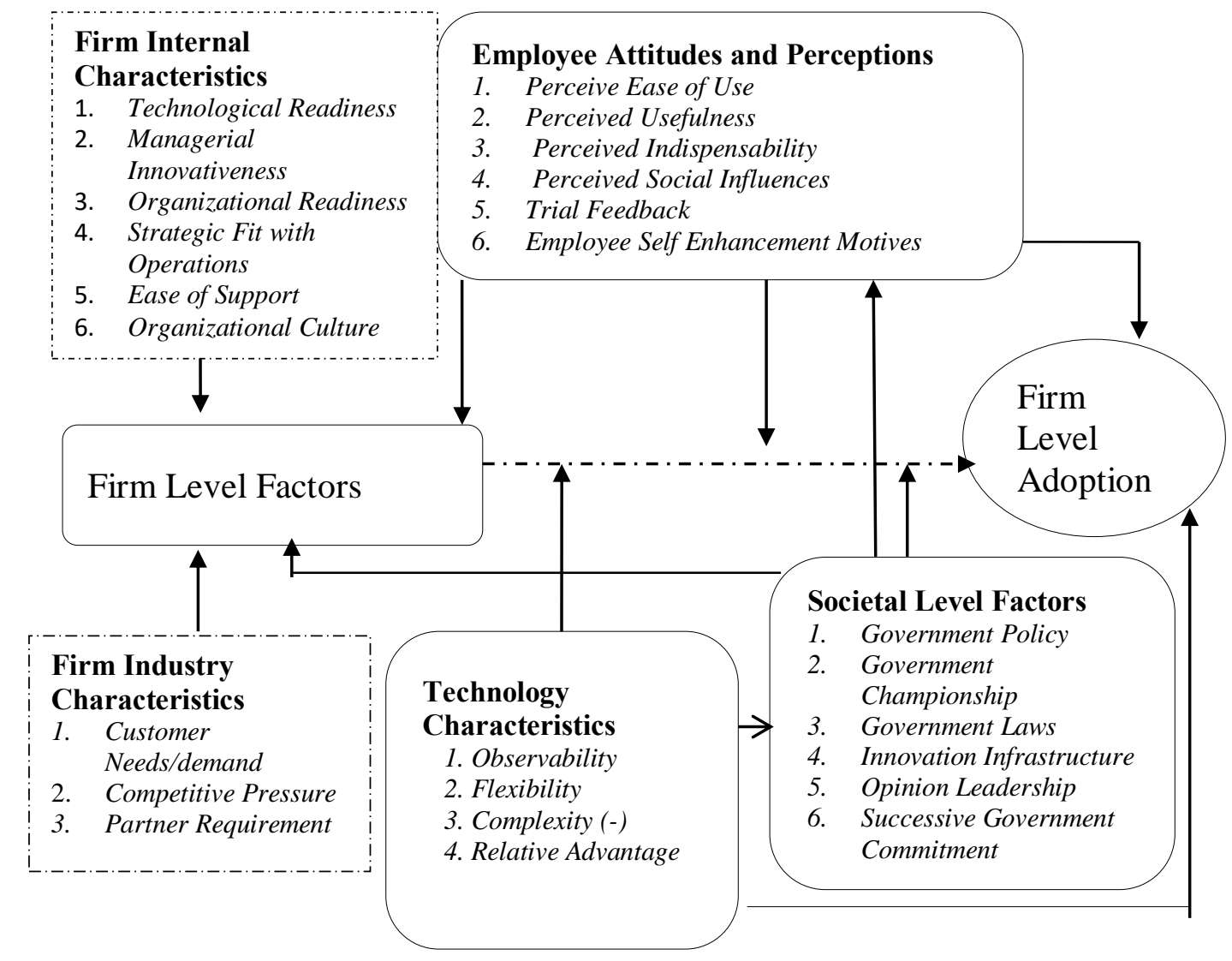

Figure 1. Survey Tested Technology Adoption Model (F-TAM)

Societal factors do not lead to firm adoption if employee factors do not mediate this relationship. These findings make employee factors probably the most significant construct in the pool of factors that engender adoption. The findings seem to challenge all models that posit that firm factors alone will lead to firm adoption. Studies that classify employees as part of the firm factors may not face this challenge.

Irrespective of government efforts concerning laws, discussions, policies, and championships made towards the adoption of an innovation, innovation will not generally be adopted if employees are not at the center of the adoption drive. Technology factors do not influence employee factors. Thus an innovation could be flexible, easy to use, give some advantages and be easy to observe. However, if its employees do not perceive the innovation as such through the lenses of the employee factors, particularly self-enhancement motives, the innovation may not be adopted. These findings may challenge models such as the DOI, wherein technology characteristics alone is suggested to lead to adoption.

This study is theoretically relevant because the study challenges the concept that any particular level of factors will lead to adoption, without reference to the adoption ecosystem. Thus for firm adoption, all dimensions of factors must be aggregated before the real factors that engender adoption can be uncovered. Our current contribution with the F-TAM, therefore, is a significant departure from earlier models. For industry practitioners, these findings illustrate the essence of putting a premium of recruiting technologically savvy employees if the firm intends to adopt digital technologies.

\section{LIMITATIONS}

This study has some limitations that future research should seek to address. First, this study employed purposive sampling (Straits \& Singleton, 2017) in data collection in order to reach small firms that have 
adopted and used mobile payment technology innovation. The downside of this sampling technique is that studies that employ this technique do not generally lend themselves to a statistical representation of the whole population. Given that the initial adopters of new technologies tend to be technology-savvy, and in most of the firms, the owner-managers lead the adoption, the findings of this study may appear to be more tailored to technologically savvy SMEs. The results may, therefore, have some minor variations for SMEs who are not technologically savvy. Again, the adoption is assumed to be a voluntary adoption process as opposed to mandatory adoption. For instance, in several government championships and policy drives, there are issues of mandatory adoption imposed on adopters. When this model is applied to SMEs who may have adopted out of mandatory adoption, varied results may be reported under such circumstances. Secondly, we took samples from the capital of the Greater Accra Region, which is assumed to be the most developed region in Ghana. The generalizability of these findings on other regions may realize minor variations. Finally, this study is based on the F-TAM model with firm adoption as the dependent variable. Although our results support the use of F-TAM in measuring the adoption of mobile digital innovations at the firm level, other satisfactory models can be applied to firm technology adoption. Any such model, however, must factor all four domains of the construct into the adoption equation. We recommend future studies with larger samples taken across the whole country and different countries. We also recommend the application of this model in mandatory adoption situations.

\section{REFERENCES}

Andersson, L.M. \& Bateman, T. S. (1997). Cynicism in the workplace: Some causes and effects. Journal of Organizational Behavior, 18 (5), 449-469.

Acheampong, P., Zhiwen, L., Antwi, H. A., Otoo, A. A. A., Mensah, W. G., \& Sarpong, P. B. (2017). Hybridizing an Extended Technology Readiness Index with Technology Acceptance Model (TAM) to Predict E-Payment Adoption in Ghana. American Journal of Multidisciplinary Research, 5(2).

Adadevoh, C. K. (2018). Factors That Influences the Adoption of E-Commerce in the Ghanaian Banking Industry. International Journal of Innovative Research and Development, 7(2).

Adjei, J. K., \& Odei-Appiah, S. (2018). Mobile Financial Services in Emerging Countries: Technology, Adoption, and Regulatory Issues. In Mobile Technologies and Socio-Economic Development in Emerging Nations (pp. 109-128). IGI Global.

Afutu-Kotey, R. L., Gough, K. V., \& Owusu, G. (2017). Young entrepreneurs in the mobile telephony sector in Ghana: From necessities to aspirations. Journal of African Business, 18(4), 476-491.

Agarwal, B. (1983). Diffusion of rural innovations: some analytical issues and the case of wood-burning stoves. World Development, 11(4), 359-376.1

Amoako, G. K., Doe, J. K., \& de Heer, F. (2014). Innovation and marketing in Africa - a Ghanaian perspective. International Journal of Technology Marketing, 9(4), 356-375.

Ansong, E., \& Boateng, R. (2018). Organisational adoption of telecommuting: Evidence from a developing country. The Electronic Journal of Information Systems in Developing Countries, 84(1), e12008.

Asongu, S. A. (2018). Conditional determinants of mobile phones penetration and mobile banking in Sub-Saharan Africa. Journal of the Knowledge Economy, 9(1), 81-135.

Brown, S. A., A. P. Massey, M. M. Montoya-Weiss, \& J. R. Burkman (2002). Do I really have to? User acceptance of mandated technology. European Journal of Information Systems (11) 4, 283-295.

Barclay, D., Thompson, R., \& Higgins, C. (1995). The Partial Least Squares (PLS) Approach to Causal Modeling: Personal Computer Adoption and Use an Illustration. Technology Studies (2:2), 285-309.

Brown, S. A., Venkatesh, V., Kuruzovich, J., \& Massey, A. P. (2008). Expectation confirmation: An examination of three competing models. Organizational Behavior and Human Decision Processes (105) 1, 52-66.

Chaouali, W., Souiden, N., \& Ladhari, R. (2017). Explaining adoption of mobile banking with the theory of trying, general self-confidence, and cynicism. Journal of Retailing and Consumer Services, 35, 57-67.

Chin, W. W. (1998). The partial least squares approach to structural equation modeling. Modern Methods for Business Research, 295(2), 295-336.

Chin, W.W. (2010), "How to write up and report PLS analyses", in Esposito Vinzi, V., Chin, W.W.,Henseler, J. and Wang, H. (Eds), Handbook of Partial Least Squares: Concepts, Methods and Application, Springer, Berlin, pp. 645-689. 
Chin, W. W., \& Newsted, P. R. (1999). "Structural Equation Modeling Analysis with Small Samples Using Partial Least Squares," in Statistical Strategies for Small Sample Research, Rick Hoyle (ed.), Thousand Oaks, CA: Sage Publications, 1999, pp. 307-341.

Cohen, J. (1988). Statistical power analysis for the behavioral sciences (2nd ed.). Hillsdale, NJ: Erlbaum

Efron, B., \& Gong, G. (1983). A leisure look at the bootstrap, the jackknife, and cross validation. The American Statistician, 37(1), 36-48.

Fornell, C., \& Larcker, D. F. (1981). Evaluating structural equation models with unobservable variables and measurement error. Journal of Marketing Research, 18(1), 39-50.

Hair, J. F.J., Anderson, R.E., Tatham, R.L., \& Black, W.C. (1998). Multivariate Data Analysis, Prentice-Hall, Upper Saddle River, NJ.

Hair, J. F.J., Ringle, C. M., \& Sarstedt, M. (2011). PLS-SEM: Indeed a silver bullet. The Journal of Marketing Theory and Practice, 19(2), 139-152.

Hair J.F.J., Sarstedt, M., Hopkins L., \& Kuppelwieser, V.G. (2014). Partial least squares structural equation modeling (PLS-SEM) An emerging tool in business research. European Business Review, 26 (2), 106-121.

Hair, J. F., Hult, G. T. M., Ringle, C. M., \& Sarstedt, M. (2016). A Primer on Partial Least Squares Structural Equation Modeling (PLS-SEM) $.2^{\text {nd }}$ edition. Thousand Oaks, CA: Sage.

Harman, H. H. (1967). Modern Factor Analysis, $2^{\text {nd }}$ ed. University of Chicago Press, Chicago, IL.

Henseler, J., Ringle, C. M., \& Sinkovics, R. R. (2009). The use of partial least squares path modeling in international marketing. In R. R. Sinkovics \& P. N. Ghauri (Eds.), Advances in International Marketing (Vol. 20, pp. 277-319). Bingley, UK: Emerald Group.

Kazi, A. K., \& Mannan, M. A. (2016). Factors affecting adoption of mobile banking in Pakistan: Empirical Evidence. International Journal of Research in Business and Social Science (2147-4478), 2(3), 54-61.

Kock, N., \& Hadaya, P. (2018). Minimum sample size estimation in PLS-SEM: The inverse square root and gamma-exponential methods. Information Systems Journal, 28(1), 227-261.

Ledden, L., Kalafatis, S.P., \& Mathioudakis, M. (2011). The idiosyncratic behaviour of service quality, value, satisfaction, and intention to recommend in higher education: An empirical examination. Journal of Marketing Management, 27(11-12), 1232-1260.

Lee, K.-H., Yang, G., \& Graham, J.L. (2006). Tension and trust in international business negotiation: American executives negotiating with Chinese executives. Journal of International Business Studies, 37(5), 623-641.

Lings, I. N., \& Greenley, G. E. (2010). Internal market orientation and market oriented behaviours. Journal of Service Management, 21(3), 321-343.

Marumbwa, J., \& Mutsikiwa, M. (2013). An analysis of the factors influencing consumers' adoption of mobile money transfer services (MMTS) in Masvingo urban Zimbabwe. Br J Econ Manag Trade, 3, 498-512.

Masocha, R., \& Dzomonda, O. (2018). Adoption of Mobile Money Sevices and the performance of Small and Medium Enterprises in Zimbabwe. Academy of Accounting and Financial Studies Journal, 22(3)

Nijssen, E.J., \& Douglas, S.P. (2008). Consumer world-mindedness, social-mindedness and store image. Journal of International Marketing, 16(3), 84-107.

Nitzl, C., Roldan, J. L., \& Cepeda, G. (2016). Mediation analysis in partial least squares path modeling: Helping researchers discuss more sophisticated models, Industrial Management \& Data Systems, 116 (9), 1849-1864

Podsakoff, P. M., MacKenzie, S. B., Lee, J. Y., \& Podsakoff, N. P. (2003). Common method biases in behavioral research: A critical review of the literature and recommended remedies. Journal of applied psychology, 88(5), 879.

Röling, N.G., Hounkonnou, D., Offei, S.K., Tossou, R., \& Van Huis, A. (2004). Linking science and farmers' innovative capacity: diagnostic studies from Ghana and Benin. NJAS - Wageningen Journal of Life Sciences, 52(3-4), 211-235.

Ringle, C. M., Wende, S., \& Will, A. (2005). SmartPLS 2.0 (M3) beta, Hamburg: http://www.smartpls.de.

Straits, B. C., \& Singleton, R. (2017). Social research: Approaches and fundamentals. Oxford University Press.

Suárez, S. L. (2016). Poor people's money: The politics of mobile money in Mexico and Kenya. Telecommunications Policy, 40(10-11), 945-955.

Tortosa, V., Moliner, M. A., \& Sanchez, J. (2009). Internal market orientation and its influence on organisational performance. European Journal of Marketing, 43(11/12), 1435-1456.

Yeboah-Boateng, E. O., \& Essandoh, K. A. (2014). Factors influencing the adoption of cloud computing by small and medium enterprises in developing economies. International Journal of Emerging Science and Engineering, 2(4), 13-20. 